Çukurova Üniversitesi Mühendislik Mimarlık Fakültesi Dergisi, 31(2), ss. 93-101, Aralık 2016

\title{
Genetik Algoritma Yaklaşımı ile Şantiye Yerleşim Planlaması
}

\author{
Mustafa ORAL ${ }^{* 1}$, Serkan KARTAL ${ }^{1}$, Emel LAPTALI ORAL ${ }^{2}$ \\ ${ }^{1}$ Çukurova Üniversitesi, Mühendislik Mimarlık Fakültesi, Bilgisayar Mühendisliği Bölümü, \\ Adana \\ ${ }^{2}$ Çukurova Üniversitesi, Mühendislik Mimarlık Fakültesi, İnşaat Mühendisliği Bölümü, Adana
}

Geliş tarihi: 01.06.2016 Kabul tarihi: 23.11.2016

\section{$\ddot{\mathbf{O} z}$}

Yapım işlerinde planlama sürecinin kritik öneme sahip belgelerinden biri olan Şantiye Yerleşim Planı (ŞYP) şantiyede hangi tesisin nereye yerleştirileceğini gösterir. Şantiye tesislerinin kurulumu bu plan temel alınarak gerçekleştirilir. Yapılacak işin büyüklüğü, süresi ve içeriğine bağlı olarak kurulması gereken binaların (atölyeler, depolar, beton tesisleri, ofisler, yemekhane, WC, yatakhane tesisleri, su ve elektrik temin tesisleri, araç bakım, onarım ve park yerleri, sosyal tesisler, dini tesisler gibi) büyüklükleri ve adetleri belirlendikten sonra şantiye alanının topoğrafik yapısı, ulaşım olanakları, kalıcı yapının şantiye içindeki yeri, olası riskler ve taşıma maliyetleri değerlendirilerek ŞYP çizilir. Bu çalışmalar sırasında kullanılacak geçici tesislerin neler olacağının belirlenmesi ve boyutlandırılması somut ve sayısal değerlere dayandırılabilirken tesislerin şantiye alanı içindeki yerleşimi, ŞYP'nı hazırlayan proje yöneticilerinin tecrübe ve inisiyatiflerine kalmaktadır. Optimum yerleşim planının hazırlanabilmesi konusunda proje yöneticilerine destek olabilecek bilgisayar tabanlı uygulamalara sektör bazında ihtiyaç duyulmaktadır. $\mathrm{Bu}$ ihtiyaç doğrultusunda yazarlar tarafindan genetik algoritma tabanlı bir şantiye yerleşim planı hazırlama programı (YERPLAN) geliştirilmiştir. Program ile ilgili detaylar bu makalede tartışılmaktadır.

Anahtar Kelimeler: Şantiye yerleşim planı, Genetik algoritma, Proje yönetimi

\section{Site Layout Planning by using Genetic Algorithm Approach}

\begin{abstract}
Site Layout Plan (SLP) that shows the position of each facility on the construction site is one of the critical documents of construction planning process. All the facilities on the site are allocated according to their position on SLP. SLPs are designed by considering; the volume of construction work, completion duration, types and numbers of temporary facilities (workshops, warehouses, concrete plants, offices,
\end{abstract}

\footnotetext{
* Sorumlu yazar (Corresponding author): Mustafa ORAL, moral@cu.edu.tr
} 
cafeteria, toilets, rest rooms, water and electricity supply facilities, vehicle maintenance and parking places, social facilities, religious facilities, etc,), as well as, topography of the site area, transportation facilities, fixed facility locations, possible risks and transportation costs. While decisions on identifications and specifications of necessary temporary facilities can be quantified deterministically, their allocations on construction site solely depend on the experiences and the preferences of construction site manager(s). Thus, decision-making software that helps to the project managers to design optimal SLPs is strongly required within the sector. Based on these needs, a SLP software tool (YERPLAN) that is based on genetic algorithm, is developed by the authors. Technical aspects and details of the methods used can be found in the manuscript.

Keywords: Construction site planning, Genetic algorithms, Project management

\section{GíRiș}

Şantiye Yerleşim Planı (ŞYP), kısaca, şantiyede hangi tesisin nereye yapılacağı veya yerleştirileceğinin gösterildiği teknik çizim olarak tanımlanabilir. ŞYP hazırlamak ve yapım süreci boyunca plana uygun tesis yerleşimi yapmak şantiyede gereksiz nakliyeleri, malzeme israfinı ve iş kazalarını azaltır.

ŞYP'nın hazırlanabilmesi için öncelikle tesislerin kullanım amacı (atölye, depo, işçi barakaları, lojmanlar, yemekhane, idari bina, araç park yerleri, tamirhane, ibadethaneler, kantin, firın, sağlık hizmeti veren yerler/revir, güvenlik binaları, sosyal tesisler), büyüklüğü ve sayısının belirlenmesi gerekir. $\mathrm{Bu}$ aşamada temel olarak aşă̆ıdaki unsurlar göz önünde tutulur.

1. Şantiye sahasının yeri, topoğrafik yapısı, iklim şartları,

2. Şantiye sahasına ulaşım olanakları, sahaya giriş-çıkış engelleri,

3. Kalıcı yapının şantiye içindeki yeri, sayısı, niteliği,

4. Projenin süresi, iş programı,

5. Şantiyede çalışacak teknik elemanların, ofis çalışanlarının ve işçilerin sayısı, şantiyede konaklama durumları,

6. Şantiyede kullanılacak iş makinelerinin özellikleri, sayısı,

7. Şantiyede depolanacak malzemelerin özellikleri, miktarları, depolama süreleri,

8. Şantiyede yapılacak imalatların özellikleri.
Yukarıda sıralanan unsurlar çerçevesinde belirlenen tesislerin şantiye sahasında yerleşimi ise iş güvenliği ve taşıma mesafeleri göz önünde bulundurularak, planı hazırlayan teknik elemanın bilgi, tecrübe ve inisiyatifi sınırları içinde gerçekleşir. Uygulamada ŞYP otomasyonu ile ilgili yaygın olarak kullanılan herhangi bir yazılım olmamakla birlikte literatür bulguları ŞYP optimizasyonu ile ilgili az sayıda da olsa çalışma olduğunu göstermektedir. Bu çalışmalardan ilki Hegazy ve Elbeltagi'nin geliştirdiği genetik algoritma tabanlı bir otomasyon modeli olan EvoSite'dır. Genetik algortima tabanlı çalışmalardan bir başkası da Sanad ve arkadaşları. tarafından gerçekleştirilmiş; bu çalışmada iş güvenliği ve çevre koşulları aynı anda göz önünde tutulmuştur [2]. Elbeltagi ve arkadaşları [3] ve Ning ve arkadaşları [4] ise şantiye yerleşiminde iş güvenliği unsurlarının yanı sıra iş programını da göz önünde tutan dinamik modeller geliştirmişlerdir. Ning ve arkadaşları'nın [4] yanı sıra Lam ve arkadaşları [5] ve Yahya ve Saka [6] tarafından geliştirilen ŞYP uygulamalarında Karınca Kolonisi yaklaşımı tercih edilmiştir. Bu çalışmada geliştirilmiş olan YERPLAN, yerleşim planı hazırlama programı, da yerleşim optimizasyonunu Genetik Algoritma yaklaşımıyla çözerken, bu çözüme ulaşabilmek için gerekli bilgileri farklı ara yüzler aracılığı ile elde etmekte, bu özelliği programa optimizasyon konusunda herhangi bir teknik bilgiye sahip olmayan şantiye 
elemanları tarafından kullanılabilme özelliği katmaktadır.

\section{YÖNTEM}

\subsection{Genetik Algoritma}

Genetik Algoritma (GA) doğada geçerli olan en iyilerin hayatta kalması kuralını temel alan sezgisel ve stokastik bir optimizasyon yöntemidir. Karmaşık, kısıt sayısı fazla ve kesin çözüm yöntemi olmayan problemlerin çözümünde bir çözüm grubu içerisinde sürekli iyileşen (problemin özelinde belirlenmiş kriterlere uyan) çözümlerin aranması temeline dayalı olarak çalışır. İyilerin seçimi için bir uygunluk fonksiyonu ve yeni çözümler üretmek için yeniden kopyalama, değiştirme gibi operatörler kullanır [7]. Problemin çözümüne ait değişken değerlerinden oluşan bir diziyi içeren alternatiflere 'kromozom' ad1 verilmektedir. Değişkenlerin her birisi ise 'gen' olarak tanımlanır. Bir problemde ne kadar karar değişkeni varsa her kromozomda o kadar gen bulunur [8]. Problem çözümünde kullanılacak birey (kromozom) sayısı 'toplum büyüklügü' olarak tanımlanmakta, toplum büyüklüğü değerinin gereğinden büyük veya küçük seçilmesi problem çözümünü zorlaştırmaktadır. Gereğinden büyük değerler sonuca geç ulaşılmasına neden olurken, küçük değerler çözümün optimum çözüm uzayı dışında aranmasına neden olmaktadır [9]. Mevcut toplumda bulunan iyi özelliklere sahip bireylerin (kromozomların) bir sonraki aşama için kullanılacak yeni topluma aktarılması da 'uygunluk değeri' ne göre yapılmaktadır. Bir kromozomun uygunluk değeri bazı araştırmacılar tarafından o kromozoma doğrudan atanırken bazı araştırmacılar ise uygunluk değerini 'uygunluk fonksiyonu' oluşturarak hesaplamaktadırlar [10]. Uygunluk fonksiyonu problemin özelliğine göre algoritmanın başında hesaplanır ve toplumdaki tüm bireylerin uygunluk değerleri belirlenir. Bireylerin uygunluk değerlerine göre üreme, çaprazlama veya mutasyon işlemleri uygulanır [11].

\section{UYGULAMA AŞAMALARI}

\section{1. Şantiye Yerleşim Planı Hazırlama Programı (YERPLAN)}

Mevcut araştırma kapsamında inşaat proje yöneticilerine şantiye yerleşim planı hazırlamada yardımcı olacak bir yazılım geliştirilmiştir. YERPLAN-Şantiye Yerleşim Planı Hazırlama Programı-yerleşimi ile ilgili bir dizi bilgi ve veriyi farklı ara yüzler aracılığı ile almakta ve bu verileri Genetik Algoritma yaklaşımı kullanarak değerlendirdikten sonra optimum yerleşim planını kullanıcıya sunmaktadır.

YERPLAN kapsamında kullanıcıdan istenilen bilgi/veriler ve ilgili ara yüzlerin içerikleri aşağıda sıralanmıştır.

1. Proje Adı: Kullanıcının karşısına çıkan ilk ara yüz 'Giriş Ekranı'dır (Şekil 1). Bu ekranda kullanıcıdan proje adının girilmesi istenmektedir. Proje ile ilgili tüm veriler girilen proje adı üzerinden kayıt edilmekte, veri girişi tamamlanmadan programdan çıkılması durumunda var olan proje adı seçilerek işlemlere istenilen yerden devam edilebilmektedir.

2. Projede Kullanılacak Tesislerin Ad ve Adetleri: Programın bu kisminda kullanıcıdan proje süresince kullanılacak geçici tesisler ile projenin konusu olan kalıcı tesislerin adları, adetleri ve boyutlarının girilmesi istenmektedir. Şekil 2'de görüldüğü gibi şantiyelerde sıklıkla kullanılan birçok tesisin adı liste halinde ekranda verilmekte, kullanıcı kendi projesinde kullanılacak tesislerin adlarını bu listeden seçebilmekte isterse listeye ekleme de yapabilmektedir. Tesislerin ad1 girildikten sonra kullanıcı Şekil 3'de gösterildiği üzere tesislerin sayılarını da değiştirebilmektedir.

3. Tesislerin Özellikleri: Şekil 2 ve 3'deki ara yüzler kullanılarak tesis adları ve adetleri girildikten sonra Şekil 4'de verilen ara yüz aracılığı ile tesislerin alanı, genişliği, şantiye yerleşim planında olması istenen rengi ve tesisin sabit mi geçici mi olduğu ile ilgili bilgilerin girilmesi istenmektedir. 


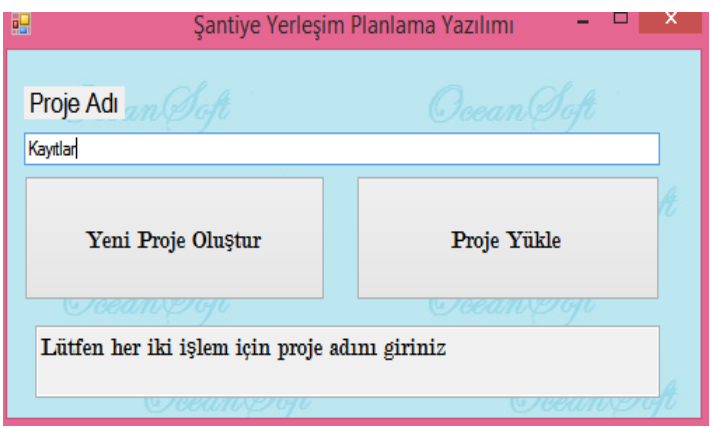

Şekil 1. YERPLAN giriş ekranı

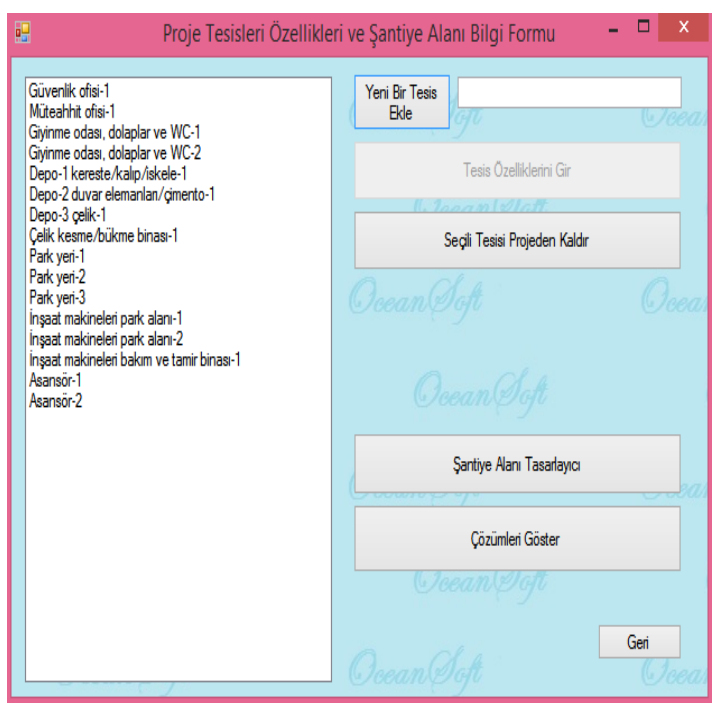

Şekil 2. YERPLAN tesis adları giriş ekranı

4. Tesisler Arasındaki Mesafeler: Şantiye tesislerinin yerleşiminde göz önünde tutulan en önemli faktör tesisler arasındaki taşıma mesafelerinin ve iş sağlığ 1 ve güvenliğini tehdit edecek risklerin aynı anda minimum tutulmasıdır. $\mathrm{Bu}$ amaçla şantiye yerleşiminde mevcut olan her bir tesis için Şekil 5'de bir örneği verilen şekilde kullanıcıdan tesisin diğer tesislerle yakınlık derecesini sisteme girmesi istenmektedir. Preston ve Colman'ın [12] yapmış oldukları çalışmada 710 seçenekten oluşan Likert ölçeklerinin en yüksek geçerlik ve güvenirlik değerlerine sahip olduklarını ortaya koymuşlardır. Bu çalışmada da, yerleşim planının en hassas ve güvenilir şekilde yapılabilmesi için yakınlık derecesinin -9, +9 aralığında değerlendirip sisteme girilmesi istenmektedir.

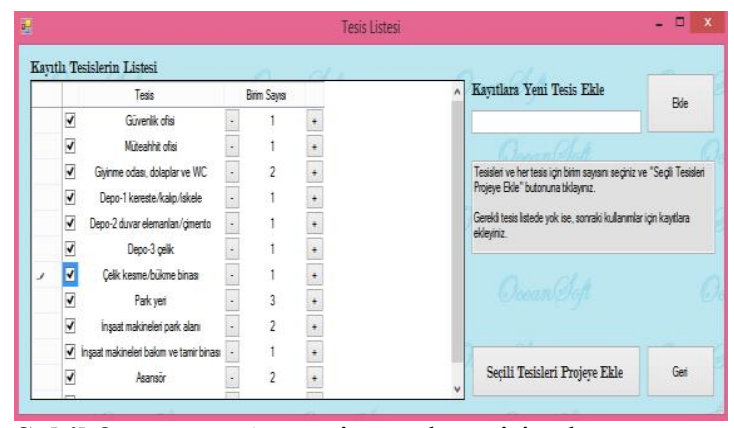

Şekil 3. YERPLAN tesis sayıları giriş ekranı

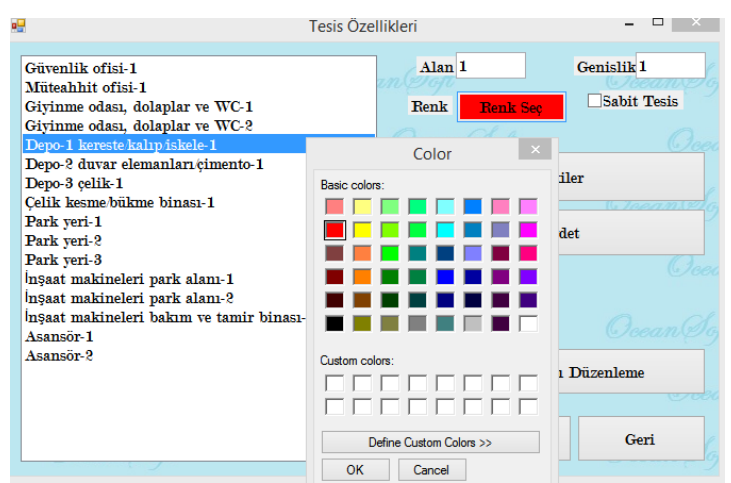

Şekil 4. YERPLAN tesis özellikleri giriş ekranı

5. Şantiye Alanının Ekran Üzerinde Çizilmesi: ŞYP'nin hazırlanabilmesi için tesis özellikleri dışında şantiye alanının şekli de gereklidir. YERPLAN'da şantiye alanı ile ilgili ara yüz 'Şantiye Alanı Tasarlayıcı' başlığı altında kareli kâğıt görünümünde kullanıcının karşısına çıkmaktadır (Şekil 6). Ekranda çıkan karelerin x ve y eksenlerinde kaçar adet olacakları kullanıcı tarafindan belirlenmektedir. Kullanıcı, belirlenen ölçeklendirme çerçevesinde kareli kâğıdın üzerine şantiyenin şeklini çizip, kaydedilmesi için 'Poligon Çiz' butonuna bastıktan sonra kullanıcının şekil üzerinde işaretleyeceği herhangi bir alan yerleşime uygun olmayan alan kabul edilip gri renge taranarak kaydedilmektedir. $\mathrm{Bu}$ düzenlemeler sırasında herhangi bir alanın yerleşime uygunluğu konusunda değişiklik yapılmak istenirse istenen bölge işaretlenip, yeniden 'Poligon Çiz' butonuna basılarak o alanın uygunluğu değiştirilebilmektedir. 


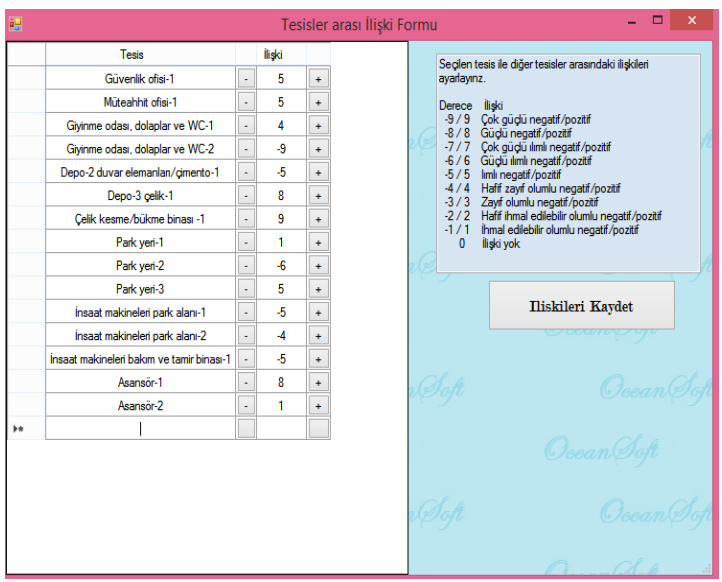

Şekil 5. YERPLAN tesisler arasında olması istenen mesafelerin ölçeklendirilmesi

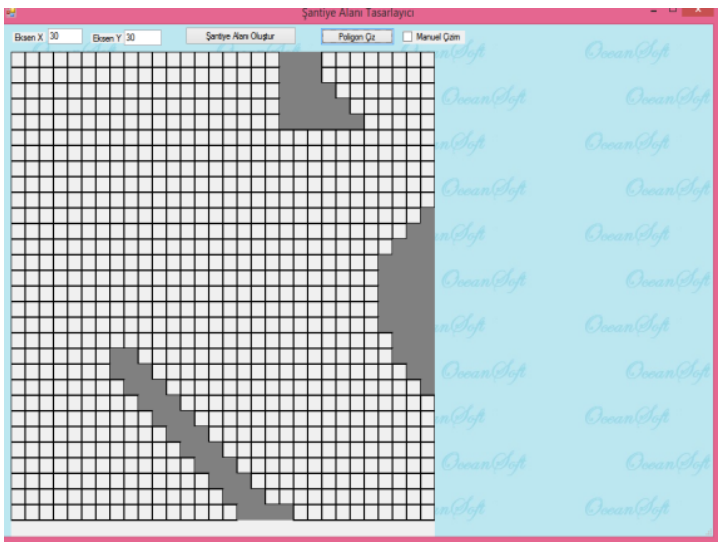

Şekil 6. YERPLAN alan düzenleme ekranı

6. Sabit Tesisin Şantiye Alanı Üzerinde Yerleştirilmesi: Şantiye alanı oluşturulduktan sonra 'Sabit Tesis Yerleştirme' ekranı aracilığı ile kullanıcıdan sabit tesis(ler)in alan üzerinde yerleștirilmesi istenmektedir (Şekil 7).

\section{GENETIKK ALGORITMA TABANLI YERLEŞIM OPTIMIZASYONU}

Sabit tesis veya tesislerin yerleştirilmesi ile şantiye yerleşimi ile ilgili bilgi/verilerin kullanıcı tarafından giriş işlemleri bitmektedir. Bu aşamadan sonra program aşağıda sıralanan Genetik Algoritma aşamalarını gerçekleştirmekte ve kullanıcıya elde ettiği optimum yerleşim planını sunmaktadır.

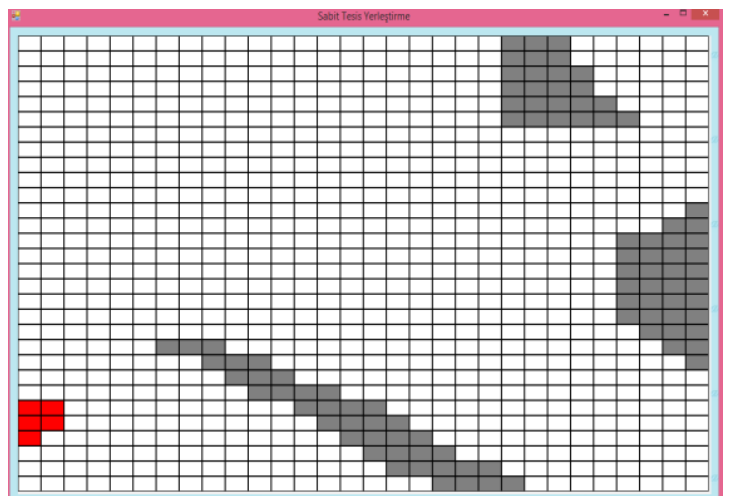

Şekil 7. YERPLAN sabit tesis yerleştirme ekranı

1. Genetik Algoritma parametrelerinin ilk değerlerinin girilmesi: Genetik Algoritmanın ihtiyaç duyduğu parametrelerin; birey sayısı, turnuva seçim metodu için turnuva büyüklüğü, çaprazlama ve mutasyon oranları gibi değerlerin kullanıcı tarafindan istenirse seçilebilmesine izin verilerek, farklı kombinasyonlarda farklı başarımların elde edilebilmesine olanak kılınmıştır. $\mathrm{Bu}$ sayede kullanıcı yazılım geliştiricinin öngördüğü kıstaslardan bağımsız olarak kendi kurgusunu test edebilecektir. Yukarıda belirtilen parametreler, Şekil 8'de verilen 'Genetik Algoritma Giriş Ekranı' aracılığıyla kullanıcı tarafindan girilir.

2. Başlangıç popülasyonun oluşturulması: Problemin kromozomu, ŞYP'na yerleştirilecek tesis sayısı kadar koordinat ikilisine sahiptir. Her ikili, yerleştirilecek olan tesisin sol üst köşesinin plan üzerindeki koordinatlarını temsil etmektedir. $\mathrm{Bu}$ nedenle kromozomdaki gen sayıs tesis sayısının tam iki katıdır. Bir kromozom, problem için önerilmiş bir çözümdür ve tesislerin kromozom üzerindeki konumları sabittir. Başlangıç çözümleri 'Genetik Algoritma Giriş Ekranı'ndan alınan birey sayısı kadardır ve harita üzerine herhangi bir kısit gözetilmeksizin rastgele yerleştirilen tesislerden oluşmaktadır. Kromozom iki parçalıdır: İlk parça sabit tesislerinin konum bilgilerini, ikinci parça ise sabit olmayan tesislerin konum ikililerini içermektedir. Birinci ve ikinci parçadaki tesislerin kromozom üzerindeki sıraları üretilen tüm çözümlerde sabit tutulmuştur. $\mathrm{Bu}$ 
özellik çaprazlama işlemi sonucunda oluşacak çocukların tamirini gerektirmeyecektir.

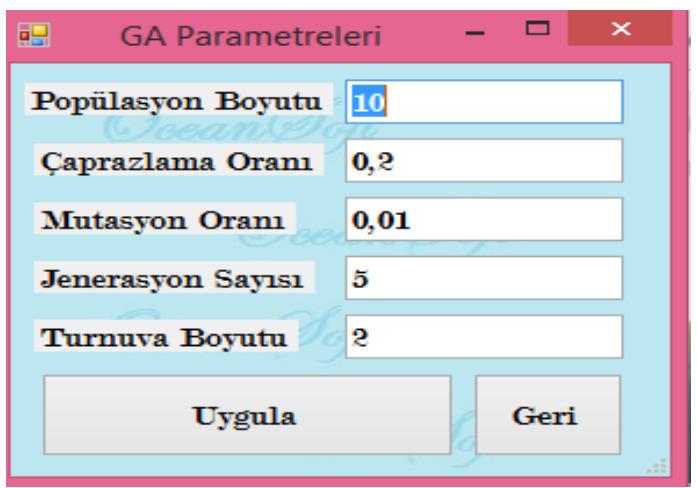

Şekil 8. YERPLAN genetik algoritma konfigürasyon ekranı

3. Tesislerin ağırlık merkezlerinin hesaplanması: Tesisleri temsil eden poligonların ağırlık merkezleri, bu poligonların zaten resim olarak çizilmiş olmasından faydalanılarak, resimlerin ağırlık merkezlerini bulmak için kullanılan moment formülleri temel alınarak hesaplanmıştır. Eğer bir resim $\mathrm{f}(\mathrm{x}, \mathrm{y})$ fonksiyonu ile ifade ediliyorsa x'e göre p'nci, y'ye göre q'ncu Genelleştirilmiş Moment (1) ile hesaplanır.

$\mathrm{m}_{\mathrm{p}, \mathrm{q}}=\sum_{\mathrm{x}, \mathrm{y}} \mathrm{x}^{\mathrm{p}} \mathrm{y}^{\mathrm{q}} \mathrm{f}(\mathrm{x}, \mathrm{y})$

Bir resmin ağırlık merkezinin $\mathrm{X}$ ve $\mathrm{Y}$ bileşenleri ise (1)'de verilen Genelleştirilmiş Moment formülünün yardımıyla, sırasıyla, (2) ve (3) ile hesaplanır (Şekil 9).

$\mathrm{x}_{\mathrm{Ag} \mathrm{ger}}=\frac{\mathrm{m}_{1,0}}{\mathrm{~m}_{0,0}}$

$\mathrm{y}_{\mathrm{AğMer}}=\frac{\mathrm{m}_{0,1}}{\mathrm{~m}_{0,0}}$

4. Kromozomu oluşturan tesislerin, birbirlerine olan uzaklıklarının hesabı: $\mathrm{Bu}$ amaçla tesislerin ağırlık merkezleri arasındaki Öklid mesafesi göz önüne alınmıștır (4). Her bir kromozom için tüm mesafeler $\mathrm{D}(\mathrm{i}, \mathrm{j})$ adı verilen iki boyutlu bir dizide sonraki çakışma hesaplarında kullanılabilmek için saklanmıştır. $\mathrm{i}$ ve j tesislerin indeks numaralarıdır.

$$
\begin{aligned}
& \mathrm{D}[\mathrm{i}, \mathrm{j}]=\left(\left(\text { Tesis. } \mathrm{i}_{\mathrm{x}_{\mathrm{AğM} M e r}}-\text { Tesis.j } \mathrm{j}_{\mathrm{x}_{\mathrm{AğMer}}}\right)^{2}+\right. \\
& \left.\left(\text { Tesis. } \mathrm{i}_{\mathrm{y}_{\mathrm{AğMer}}}-\text { Tesis. } \mathrm{j}_{\mathrm{y}_{\mathrm{A} \breve{g} M e r}}\right)^{2}\right)^{-\frac{1}{2}}
\end{aligned}
$$

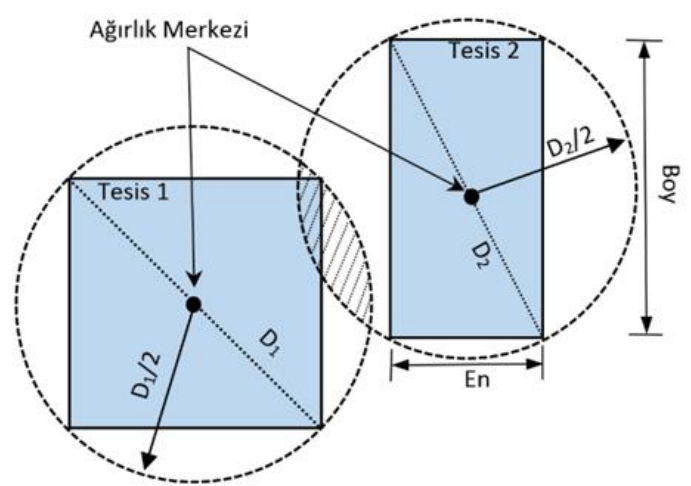

Şekil 9. Tesislerin çakışma testi için diyagonal uzunluklarının hesabı

5. Her tesis için tesis köşegen uzunluğunun hesaplanması: Köşegenlerin hesabı tesislerin yerleşiminde çakışmaların tespit edilmesinde kullanılmaktadır. Şekil 9'da verilen Tesis1 ve Tesis2 için Köşegen uzunlukları, sırasıyla D1 ve D2 ile gösterilmiştir. Tesis Diyagonal uzunluğu (Dn), tesisi içerisine alan bir dikdörtgenin eni ve boyu kullanılarak Pisagor teoreminden hesaplanır.

6. Her kromozom için tesis çakışmalarının hesaplanması: Tesis çakışmalarında iki durum göz önünde bulundurulmaktadır. Bunlar Tesis-Tesis çakışması ve Tesis-Yasaklı Alan Çakışması olarak adlandırılmıştır.

Tesis-Tesis çakışmasında tesislerin ağırlık merkezini merkez alan Dn/2 yarıçapında çizilen çemberlerin birbirlerini kesip kesmediği kontrol edilir. Bu hesap maliyeti açısından ucuzdur ve hızlı bir şekilde sonuçlanır. Çemberler kesişmiyor ise çakışma kesinlikle yok demektir. $\mathrm{Bu}$ durumda bu yerleşimin kalitesi tesislerin birbirlerine olan yakınlıkları ile ilişkilidir. İki tesis arasındaki Yakın 


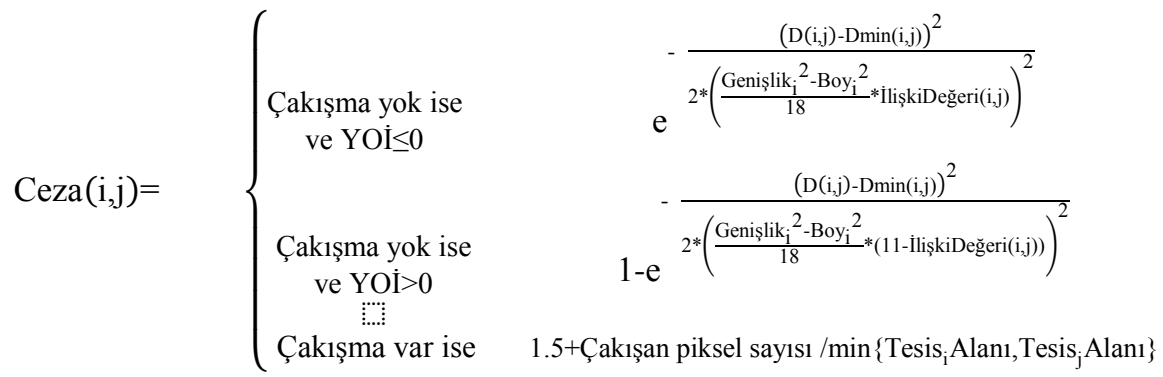

Olma İlişkisi'nin (YOİ) kullanıcı tarafında negatif (uzak olmalılar) ya da pozitif olarak belirlenmiş olması durumunda Tesis(i) ve Tesis(j)'nin yerleşiminden elde edilecek ceza puanı Ceza $(i, j)$ (5) kullanılarak hesaplanır.

Burada $\mathrm{D}(\mathrm{i}, \mathrm{j})$ iki tesis ağırlık merkezleri arasındaki Öklid mesafesini, Dmin(i,j) iki tesisin birbirlerini kesmeden yan yana bulunabilecekleri minimum mesafeyi, İlişkiDeğeri(i,j) ise iki tesis arasındaki Yakın Olma İlişkisini göstermektedir. Eğer çemberlerde bir kesişme var ise bu durumda hesap daha pahalı yöntemlere dayanır. Fakat unutulmaması gerekir ki çemberlerin kesişmesi iki tesisin kesin olarak çakıştığ 1 anlamı taşımamaktadır. Tesis yerleşim planından her iki tesisi içerisine alacak şekilde bir parça koparılır ve burada görüntü işleme teknikleri yardımıyla tesislerin kesişen parçalarının piksel sayısı hesaplanır. Çakışmanın olmaması durumunda piksel sayısı sıfır çıkacak ve çakışma yoktur olarak belirlenerek ceza puanı (5) den hesaplanacaktır. Çakışmanın var olması durumunda, Çakışma miktarı/Tesis alanı oranlarına bakılır. Bu oran her zaman birden küçük bir değer üretir. İki tesisten hangisinde bu oran daha büyük ise bu değere 1,5 eklenerek ceza hesabında kullanılır.

Tesis-Yasaklı Alan çakışmasında ise (5) eşitliğinin çakışmanın var olma koşulundaki adımları uygulanır.

7. Kromozom Uygunluk Hesabı: Tüm TesisTesis, Tesis-Yasaklı Alan çiftleri arasında hesaplanan ceza puanlarının toplamı önerilen çözümün uygunluk değeridir (6). Uygunlukb b. bireyin çözüm içerisindeki toplam ceza puanıdır. $\mathrm{Bu}$ puanın minimum olması istenmektedir.
Uygunluk $_{b}=\sum_{i=1}^{\text {Tesis Sayısl }} \sum_{j=1}^{\text {Tesis Sayısı }}$ Ceza $(i, j)$

8. Turnuva Metodu (TM) ile ebeveyn seçimi: Popülasyon içerisinden Turnuva Büyüklüğü sayısı kadar birey rastgele seçilerek bu bireylerden en az ceza puanına sahip olan çözüm birinci ebeveyn olarak belirlenir.

9. Çaprazlama: TM ile elde edilen birey ya doğrudan bir sonraki nesle aktarılır ya da yine TM ile ikinci ebeveyn seçilerek çaprazlama işlemine geçilir. Bu amaçla; [0,1] aralığında rastgele seçilen bir sayısal değerin çaprazlama oranından büyük olması durumunda birinci ebeveyn doğrudan bir sonraki nesle aktarılır, küçük eşit olması durumunda ise ikinci ebeveyn seçilerek çaprazlama işlemi uygulanır. Çaprazlama için ise tek noktadan çaprazlama yöntemi seçilmiştir. Tek noktadan ikiye ayrılan gen parçaları çapraz birleştirilerek iki çocuk üretilir ve uygunluk değerleri hemen hesaplanır. Daha iyi olan çocuk bir sonraki nesle aktarılır daha kötü olan çocuk yok edilir. Böylece bir sonraki nesli oluşturacak bireylerin çözüm nitelikleri geliştirilmiş olur.

10. Mutasyon işlemi: Gelecek neslin tamamı elde edildikten sonra bireyler için yine $[0,1]$ aralığında rastgele bir sayı üretilir. $\mathrm{Bu}$ sayının mutasyon oranından büyük olması durumunda birey mutasyona uğratılmaz. Eğer sayı mutasyon oranından küçük ve eşit ise bu durumda sabit olmayan tesislerden birisinin koordinatları yerleşim planı üzerinde rastgele bir noktaya taşınır. $\mathrm{Bu}$ işlem çözümün yerel minimuma takılmasının önüne geçmek ve arama işleminin sürdürülebilirliğini sağlamak için gereklidir. Her popülasyonun en iyi bireyi her zaman bir sonraki nesle doğrudan aktarılır ve üzerinde mutasyon 
işlemine izin verilmez. Böylece o ana kadar elde edilmiş en iyi birey hiçbir zaman kaybolmaz ve algoritma sonlandığında tüm jenerasyonlarda elde edilmiş en iyi çözümün son popülasyon içerisinde kalması sağlanmış olur.

11. Algoritmanın sonlanması: Tüm iterasyonlar sonucunda çakışmaların olmadı̆̆ı bir çözüm üretilmiş ise bu çözüm ŞYP olarak kullanıcıya sunulur. Eğer bir çözüm bulunamamışsa son popülasyondaki bireylerin $\% 25{ }^{\prime} i$ doğrudan aktarılmak üzere yeniden bir başlangıç popülasyonu oluşturularak işlemler tekrar edilir. Her on tekrarda kullanıcıdan aramaya devam edilip edilmeyeceği sorulur.

12. Şantiye yerleşim planının elde edilmesi: Genetik algoritma sonuçları elde edildikten sonra şantiye yerleşim planı Şekil 10'daki örnekteki gibi görsel olarak elde edilmektedir. Örnekte gri renk yerleşime uygun olmayan alanları, kırmızı renk sabit bir tesisi (güvenlik ofisi), yeşil renk park yerini, turkuaz renk müteahhit ofisini, pembe renk inşaat makineleri park alanını, mavi ve sarı renkler ise giyinme odalarının bulundukları tesisleri göstermektedirler.

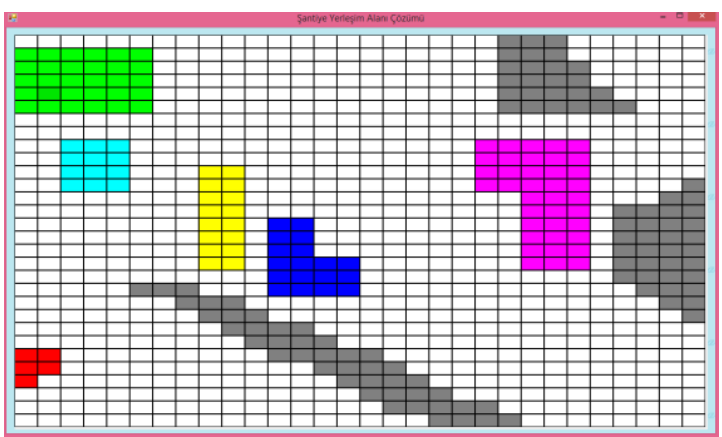

Şekil 10. Şantiye yerleșim planı çıktı ekranı

\section{SONUÇ VE ÖNERILLER}

Bu çalışma kapsamında Genetik Algoritma tabanlı bir şantiye yerleşim planı hazırlama yazılımı (YERPLAN) tanıtılmıştır. Literatürdeki var olan benzer uygulamalar, maliyet fonksiyonunda tesislerin kullanım frekansları ve tesisler arasındaki mesafelere bağlı olarak kat edilen taşıma ve yürüme mesafelerini minimuma indirgemeye çalışırken, YERPLAN, uzman görüşüne dayanan ve her iki kavramı (kullanım sıklığı ve tesisler arası mesafeler) tek bir ilişki matrisi üzerinde birleştirmeyi başarmış ve verimli sonuçlar elde edilmiştir. Ayrıca tesis çakışma testlerinde görüntü işleme yordamlarının kullanımı da bu bağlamda bir yenilik sunmaktadır.

İleriki çalışmalarda, tesisler arasında olması gereken güvenli mesafenin sağlanması, tehlikeli maddelerin güvenli depolanması ve düşebilecek cisimlerin yer aldığı tesislerin uygun bir şekilde konumlandırılması gibi kriterler göz önünde bulundurularak çalışmanın iş sağlığı ve güvenliği kavramlarını da bünyesinde barındıracak şekilde genişletilmesi hedeflenmiştir.

\section{TEŞEKKÜR}

$\mathrm{Bu}$ Çalışma Ç. Ü. Araştırma Projeleri Birimi Tarafindan Desteklenmiştir. (Proje No: FBA-20165916).

\section{KAYNAKLAR}

1. Hegazy, T., Elbeltagi, E., 1999. EvoSite: An Evolution-Based Model for Site Layout Planning, Journal of Computing in Civil Engineering, 13 (3),198-206.

2. Sanad, H., Ammar, M., Ibrahim, M., 2008. Optimal Construction Site Layout Considering Safety and Environmental Aspects, Journal of Construction Engineering and Management, 134(7), 536-544.

3. Elbeltagi, E., Hegazy, T., Eldosouky, A., 2004. Dynamic Layout of Construction Temporary Facilities Considering Safety, Journal of Construction Engineering and Management, 130(4), 534-541.

4. Ning, X., Lam, K.C., Lam, M.C.K., 2010. Dynamic Construction Site Layout Planning Using Max-Min Ant System, Automation in Construction, 19(1), 55-65.

5. Lam, K.C., Ning, X., Ng, T., 2007. The Application of the Ant Colony Optimization Algorithm to the Construction Site Layout Planning Problem, Construction Management and Economics, 25(4), 359-374. 
6. Yahya, M., Saka, M.P., 2014. Construction site Layout Planning Using Multi-Objective Artificial Bee Colony Algorithm With Levy Flights, Automation in Construction, 38, 14-29.

7. Oral, M., Oral (Laptalı) E., Bozkurt S., Erdiş E., 2003. Yapım Projelerinde Genetik Algoritma Kullanarak Kaynak Seviyeleme, Çukurova Üniversitesi Mühendislik Mimarlık Fakültesi Dergisi, 18,2, 185-195.

8. Şen, Z., 2004. Genetik Algoritmalar ve En İyileme Yöntemleri, Su Vakfı Yayınları, İstanbul.

9. Goldberg, D.E., Deb, K. Clark., J.H., 1992. Genetic Algorithms, Noise, and the Sizing of Populations. Complex Systems, 6, 333-362.

10.Goldberg, D. E., Deb, K. ve Clark., J. H., 1992. Genetic Algorithms, Noise, and the Sizing of Populations. Complex Systems, 6, 333-362.

11.Chan, W., Zeng, Z., 2005. Rescheduling Precast Production with Multi objective Optimization, Computing in Civil Engineering, 1-1

12.Preston, C.C., Colman, A.M., 2000. Optimal Number of Response Categories in Rating Scales: Reliability, Validity, Discriminating Power, and Respondent Preferences. Acta Psychologica, 104, 1-15. 
